\title{
Pupils' Attitude Towards Learning Mathematics Subject in Nkasi District Primary Schools
}

\author{
Geofrey Mwanahanja ${ }^{1}$, Frank Tilya ${ }^{2}$ \\ ${ }^{1}$ Department of General Studies, Water Institute, Dar es Salaam, Tanzania \\ ${ }^{2}$ School of Physical Sciences, University of Dodoma, Dodoma, Tanzania
}

Email address:

gmwanahanja@gmail.com (G. Mwanahanja), ftilya@gmail.com (F. Tilya)

\section{To cite this article:}

Geofrey Mwanahanja, Frank Tilya. Pupils' Attitude Towards Learning Mathematics Subject in Nkasi District Primary Schools. International Journal of Education, Culture and Society. Vol. 5, No. 2, 2020, pp. 20-25. doi: 10.11648/j.ijecs.20200502.11

Received: May 16, 2019; Accepted: April 16, 2020; Published: April 28, 2020

\begin{abstract}
An attitude is all about emotions, beliefs, and behaviors toward a particular object, person, thing, or event. It is the result of experience. Attitude has a powerful influence over learning. The study aimed at determining attitudes of pupils towards learning mathematics, and thereupon establish possible linkages between attitudes and performance. A cross-sectional survey study was employed to answer two research questions. The questionnaires, focused group discussion, semi-structured interviews and documentary review were used to gather information from 320 pupils and 77 teachers. The descriptive statistics in contingence tabulation used to test the association of the results at $5 \%$ level of association. The findings show that the majority of pupils have positive attitude toward learning mathematics subject. Similarly, a large number of teachers have positive attitude towards pupils learning mathematics subject. Nevertheless, pupils' attitude towards learning mathematics was not directly linked to their academic performance. Poor performance was found to be caused by poor teaching and learning environment in primary schools. In due regard, further research is needed in the same study in other districts of Tanzania for comparative reason and generalization. For the immediate action, the government should facilitate empowerment of mathematics teachers through short courses, seminars, workshops and any other professional development programmes in order to improve their ability in teaching the subject. Furthermore, teaching and learning environment should be improved for effective learning.
\end{abstract}

Keywords: Pupils' Attitude, Learning Mathematics, Mathematics Performance, Professional Teachers

\section{Introduction}

Education is the foundation of economic, political development and social stability in any country. The government of Tanzania has formulated Primary Education Development Programme (PEDP) as a means of improving primary education quantitatively and qualitatively as a sustainable strategy for achieving the Millennium Development Goals 2015 and Tanzania Development Vision 2025 [1]. Through this programme, enrolment rate in both pre- primary and primary schools increased tremendously and the number of primary schools together with qualified teachers also increased. Consequently, Tanzania received a special prize from the United Nations for excelling in enrolling an increased number of primary school pupils.

While the enrolment of pupils has constantly been increasing, the performance in Mathematics (Hisabati in
Swahili) in primary schools leaving examinations (PSLE) has been very poor in comparison to Kiswahili and Social Studies (Maarifa ya jamii in Swahili). The performance in Mathematics in Tanzania has been worsening year after year (see Table 1). Though in the last three years there has been improvement in mathematics pass rate, however, mathematics is the worse performed subject in PLSE. The weighted passed percentages of PLSE subject performance in 2007-2017 for Mathematics, Social Studies and Kiswahili are $37.20 \%, 60.24 \%$ and $72.73 \%$ respectively.

The high rates of failure in Mathematics in primary school inhibit the pupils from studying the subject in ordinary level secondary schools. As a result, that deprives pupils the opportunity for later enrolment in Mathematics-related fields in advanced secondary schools and eventually in higher learning institutions. Hence, the countrywide dwindling number of professionals in science and technology sectors. 
[2] argued that, student's constant failure in a school subjects and Mathematics in particular can make the learner believe will never do well on the subject, thus declaring defeat. On the other hand, pupils' successful experience can make him/her to develop a positive attitude towards learning the subject. According to [3], negative attitude towards Mathematics leads to Mathematical anxiety or fear. Moreover, the high anxiety in Mathematics leads pupils to [4]. Therefore, it is obvious that, constant failure in Mathematics can be attributed to negative attitude towards the subject.

Table 1. General Performance in Primary Leaving Examination in Tanzania for Three Selected Subjects Among Five from 2007 to 2017.

\begin{tabular}{|c|c|c|c|c|}
\hline \multirow[b]{2}{*}{ Years } & \multirow[b]{2}{*}{ Remarks/Status } & \multicolumn{3}{|l|}{ Subjects } \\
\hline & & $\begin{array}{l}\text { 'Hisabati' } \\
\text { Mathematics }\end{array}$ & $\begin{array}{l}\text { 'Maarifa' } \\
\text { Knowledge }\end{array}$ & Kiswahili \\
\hline \multirow{3}{*}{2007} & Sat & 773,278 & 773,156 & 773,120 \\
\hline & Pass (A-C) & 134,705 & 436,000 & 620,274 \\
\hline & Percentage & 17.42 & 56.39 & 80.23 \\
\hline \multirow{3}{*}{2008} & Sat & $1,017,622$ & 1017565 & 1017650 \\
\hline & Pass (A-C) & 183,866 & 620972 & 747102 \\
\hline & Percentage & 18.07 & 61.03 & 71.41 \\
\hline \multirow{3}{*}{2009} & Sat & 998234 & 998188 & 998225 \\
\hline & Pass (A-C) & 209,092 & 593489 & 689607 \\
\hline & Percentage & 20.95 & 59.46 & 69.08 \\
\hline \multirow{3}{*}{2010} & Sat & 894665 & 894699 & 894693 \\
\hline & Pass (A-C) & 221,013 & 608527 & 635432 \\
\hline & Percentage & 24.70 & 68.01 & 71.02 \\
\hline \multirow{3}{*}{2011} & Sat & 973512 & 973510 & 973520 \\
\hline & Pass (A-C) & 383,221 & 533961 & 667671 \\
\hline & Percentage & 39.36 & 54.85 & 68.58 \\
\hline \multirow{3}{*}{2012} & Sat & 864928 & 864988 & 864880 \\
\hline & Pass (A-C) & 162078 & 247448 & 354588 \\
\hline & Percentage & 18.74 & 28.61 & 41.00 \\
\hline \multirow{3}{*}{2013} & Sat & 844690 & 844708 & 844704 \\
\hline & Pass (A-C) & 241741 & 447657 & 583348 \\
\hline & Percentage & 28.62 & 53.00 & 69.06 \\
\hline \multirow{3}{*}{2014} & Sat & 791869 & 791940 & 791924 \\
\hline & Pass (A-C) & 297411 & 454043 & 552003 \\
\hline & Percentage & 37.56 & 57.33 & 69.70 \\
\hline \multirow{3}{*}{2015} & Sat & 763493 & 763510 & 763500 \\
\hline & Pass (A-C) & 378502 & 472939 & 589425 \\
\hline & Percentage & 49.58 & 61.94 & 77.20 \\
\hline \multirow{3}{*}{2016} & Sat & 789166 & 789187 & 789127 \\
\hline & Pass (A-C) & 367866 & 605318 & 606145 \\
\hline & Percentage & 46.61 & 76.70 & 76.81 \\
\hline \multirow{3}{*}{2017} & Sat & 909865 & 909877 & 909884 \\
\hline & Pass (A-C) & 492257 & 570781 & 790292 \\
\hline & Percentage & 54.10 & 62.73 & 86.86 \\
\hline
\end{tabular}

Source: National Examinations Council of Tanzania Data.

Attitudes are connected to Bandura's [5] social cognitive learning theory as one of the personal factors that affect learning [6]. Bandura emphasizes the personal or self-system which controls learning by influencing intentional processes, schematic processing of experiences, memory representation and reconstruction, cognitively-based motivation, emotion activation, psycho-biologic functioning and the ease and skill to which these are employed to deal with everyday life experiences [7]. "The learner has the power to influence their own learning in new situations by controlling the environment around them (whether that environment is imposed, selected or constructed)" [8].

This theory supposes that people self-regulate their environments and actions, and that new behaviors are learned and maintained by those interactions between the person and their environment. Individual life experiences and environmental influences (like the easiest performed subject), influence each other and must be accounted for together.

Social cognitive learning theory provides a framework for multilevel approaches to Mathematics good performance promotion. It is in the mainstream of attitude research. Its theoretical approaches remain conceptually intriguing to investigators because of its breadth and unique focus on the functional bases for attitudes. This theory combines behaviorist reinforcement theory and cognitive psychology to describe the learning process in individuals.

On other hand social judgment theory focuses on how people's prior attitudes distort their perceptions of the positions advocated in persuasive messages, and how such perceptions mediate persuasion [9]. In general terms, the theory assumes that person's own attitudes serve as a judgmental standard and anchor that influences where along a continuum a persuader's advocated position is perceived to lie [10]. According to [11], an individual's initial attitude serves as an anchor for the judgment of related attitude communications. Figure 1 summarizes the major attributes of the framework that served as a model for directing the research.

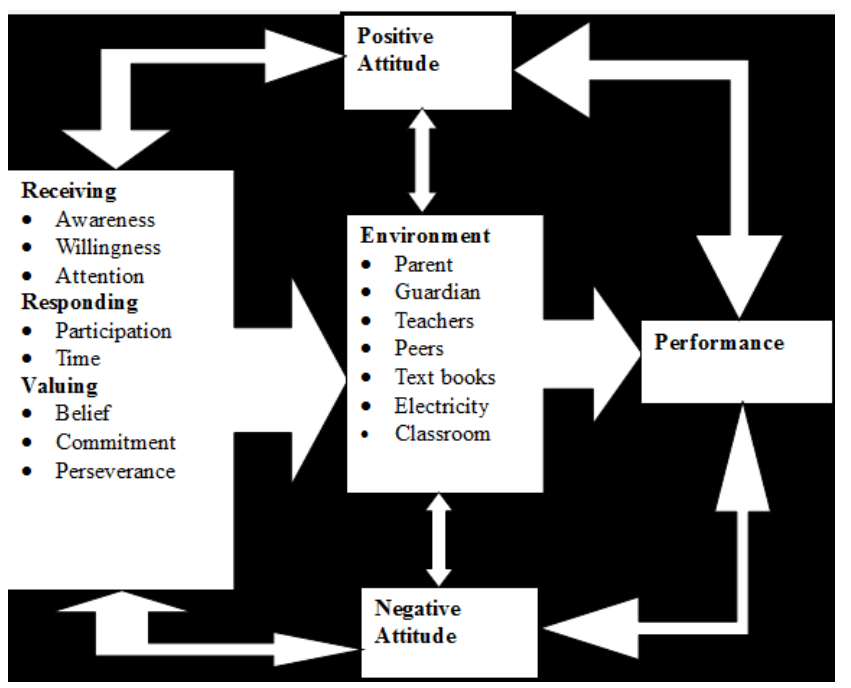

Source: Researcher, (2010)

Figure 1. Major attribute of attitude towards Mathematics.

While many researchers $[12,13,14,15]$ in Tanzania have expressed interest in this problem, especially in the effects of attitudes on learning Mathematics and performance for both sexes, a number of methodological has seriously limited them. The common characteristic of all these studies were conducted in secondary schools and very little is known in primary education. 
Therefore, the main purpose for this study was to investigate primary school pupils' attitude towards Mathematics with reasons for such attitude, and proposing ways for fostering more positive attitude towards Mathematics learning.

\section{Methodology}

This study employed mixed methods approach and concurrent triangulation design in which qualitative and quantitative data were collected concurrently in one phase. And then the data was analyzed separately and then compared and combined.

Participants were 320 Standard VI and VII primary schools' pupils, and 77 primary school teachers. They were from one private and nine public schools from Nkasi district representing $10 \%$ all primary schools in the district. The schools were co-education and the sample included sixteen (16) pupils from each class to make thirty two pupils from each school (16 girls and 16 boys).

Stratified random sampling was used in which class; gender and occupation were the strata. In each class, two groups (girls and boys) were divided equally and selected randomly. Teachers were selected randomly. It was expected that eight teachers from the sampled schools would participate. Nevertheless, teachers who responded to the questionnaire in some schools were less than expected. Moreover, two Mathematics teachers from each school were interviewed thus at least twenty mathematics teachers participated in the whole study.

Most data were collected using a structured standardized questionnaire with both open and close-ended questions. Semi-structured interview and focused group discussion were conducted to collect information that a questionnaire couldn't capture. Data were also obtained through documentary evidence, which was mainly annual examination results from school head offices and academic offices.

The instruments were piloted in one primary school in Kinondoni District, Dar es Salaam. The comments and adjustments suggested were accommodated accordingly in the final instruments. On the other hand, the reliability of questionnaire instrument had a Cronbach's alpha coefficient of 0.72 .

The attitudes towards Mathematics were measured using a 5-point Likert scale. An initial pool of 20 Likert-type attitudinal statement items regarding attitudes toward Mathematics was constructed. Some items were positively worded and others negatively worded. A principal factor analysis with varimax rotation was then used to create the factor structure of the 20 questions included in the scale. This analysis was used to reduce a set of observed variables into a relatively small number of components that account for most of the observed variance [16]. To determine the optimum factor solution, the following criteria were used; computation of the percentage of variance extracted on the one hand and interpretability of the factors on the other hand [17]. A factor loading with absolute value greater than 0.50 was considered sufficiently high to assume a strong relationship between a variable and the given factor. In addition, it was decided that factors with only one or two items and have reliability alpha less than 0.6 , even with loadings greater than 0.50 , would be excluded from the final version of the scale.

Furthermore, with respect to determining the number of factors, only factors with Eigen values greater than 1 were considered as significant $[18,19]$. Finally, the factors that were developed from this study were analyzed further with the use of descriptive and correlation. The results from focus group discussion and interviews were analyzed by using simple calculation of frequencies, percentages of the pupils' and teachers' responses and quotations made by respondents.

The documentary review data (examination scores) was first grouped into class size of 10 starting with the class interval $0-10 \%$. The groups were divided into two parts, those pupils having marks $50 \%$ to $100 \%$ were considered as good performer, and $0 \%$ to $49 \%$ were considered as poor performer. Then the frequency analysis was conducted. In order to establish the relationship between the pupils 'attitude towards Mathematics and pupils' performance in Mathematics, the Likert scores 4 and 5 of the scale were taken as positive attitude while scores less than 4 were considered as the negative attitude. The scores 4 and 5 in the scale represented agree and strongly agree respectively. Thus, any respondent with those scores in any statement with positive wording was considered to have positive attitude.

\section{Findings}

The results of the factor analysis produced three factors solution. The first factor was clearly the most important one since it accounted for $27.93 \%$ of the total attitude toward Mathematics scale variance and included items describing tension, stress, fear, difficulties in understanding Mathematics, and was called 'Mathematics anxiety'. This factor consisted of eight items. The two questions with the highest loadings on this factor were those of 'Mathematics makes me uncomfortable' and 'I am apprehensive of Mathematics examination.'

The second factor accounted for $12.94 \%$ of the variance had to do with the students' opinions about the importance of Mathematics. This factor consisted of 4 items (statements), while the two items with the highest loadings on this factor were those of 'Mathematics increase my curiosity' and 'everything learned in Mathematics has benefit in my daily life'. This factor therefore named 'importance of Mathematics'. This importance interpreted as the perception that pupils have in terms of how Mathematics will be useful and help them in their lives.

The third factor that was composed of three items accounted for $7.3 \%$ of the variance labeled as interest to Mathematics'. The two statements with the highest loadings on this factor were those of 'I love Mathematics' and 'I enjoy Mathematics classes.' 
Table 2. Means, Standard Deviations and Median $(N=482)$.

\begin{tabular}{llll}
\hline Factors & mean & Standard Deviation & Median \\
\hline Mathematics Anxiety & 3.9 & 1.0 & 4 \\
Importance of Mathematics & 4.2 & 0.8 & 4 \\
Interest to Mathematics & 4.4 & 0.9 & 5 \\
\hline
\end{tabular}

The median scores for all factor is above 3 which is on positive direction of the scale of five dimensions (table 2). The factor that deviate the most from the median (having median of 5) was interest to Mathematics, indicating that the pupils truly are highly intrinsically motivated to learn Mathematics and they do value it mostly. Supporting to this, all pupils (100\%) during focus group discussion, commented that Mathematics is a good and very interesting subject.

Moreover, pupils during focus group discussion agreed that Mathematics is very important subject in human life. For example, one of the respondents said that:

"Maisha ya mtu yatakuwa ya ufanisi mkubwa sana kama atakuwa na maarifa na ujuzi wa hisabati, kwa kuwa atakuwa ni mtu wa mipangoilio mizuri kwakila jambo analolifanya."

In English translation, the respondent said that, "A person who has Mathematics knowledge and skills will have a successful life in all aspects since whatever he/she is doing will be well planned.

Similarly, 95\% of Mathematics teachers responded to the interview agreed that, every pupil should learn Mathematics. This is because Mathematics develops thinking ability that is helpful on the environment manipulating. That is to say, teachers value Mathematics and need their pupils to learn Mathematics and perform better in it.

Correlation coefficients between the attitudes toward Mathematics sub-scales were also calculated. As presented in Table 3, the inter-correlations of the attitudes toward Mathematics factors suggested the following pattern of interrelationships. There was a positive correlation between Mathematics anxiety and interest to Mathematics $(r=0.36)$. Likewise, the importance of Mathematics had a positive correlation with the interest to Mathematics $(\mathrm{r}=0.44)$. Finally, the Mathematics anxiety was weakly correlated with the importance of Mathematics $(\mathrm{r}=0.25)$.

Table 3. Inter-correlations between the three factors $(N=482)$.

\begin{tabular}{llll}
\hline & Mathematics Anxiety & Importance of Mathematics & Interest to Mathematics \\
\hline Mathematics Anxiety & 1.000 & - & - \\
Importance of Mathematics & $0.247^{* *}$ & 1.000 & - \\
Interest to Mathematics & $0.364^{* *}$ & $0.443^{* *}$ & 1.000 \\
\hline
\end{tabular}

${ }^{* *} \mathrm{p}<0.01$ for all correlations

Furthermore, it was found that, relatively many pupils perform poorly in Mathematics, with only $43 \%$ perform more than or equal to $50 \%$. About $57 \%$ of the respondents (pupils) perform less than $50 \%$ (table 4 ).

Table 4. Pupils' Performance in Mathematics by percentage $(N=482)$.

\begin{tabular}{llll}
\hline Marks in percent & Frequency & Percent & Cumulative Percent \\
\hline $0-9$ & 21 & 4 & 4 \\
$10-19$ & 39 & 8 & 12 \\
$20-29$ & 50 & 10 & 22 \\
$30-39$ & 76 & 17 & 39 \\
$40-49$ & 87 & 18 & 57 \\
$50-59$ & 60 & 12 & 69 \\
$60-69$ & 54 & 11 & 80 \\
$70-79$ & 44 & 9 & 89 \\
$80-89$ & 38 & 8 & 97 \\
$90-100$ & 13 & 3 & 100 \\
\hline
\end{tabular}

However, table 5 reports that, 52 responded (11\%) having negative attitude towards Mathematics; 22 (42\%) out of these 52 respondents have good performance, while 30 (58\%) of them have poor performance in annual examination. In addition to that, within positive attitude, most of the students $57 \%$ performed poorly in annual examinations. This result implies that there was no relationship of attitude and performance. According to the focus group discussion and interview, performance influenced by other factors such as learning environment and community.
Table 5. Performance and Attitude Cross tabulation $(N=482)$.

\begin{tabular}{|c|c|c|c|c|c|}
\hline & \multicolumn{2}{|c|}{ ATTITUDE } & & \multicolumn{2}{|c|}{ PERFORMANCE } \\
\hline & $\mathbf{N}$ & $\%$ & & $\mathbf{N}$ & $\%$ \\
\hline \multirow{2}{*}{ Positive } & \multirow{2}{*}{430} & \multirow{2}{*}{89} & Good Performance & 187 & 43 \\
\hline & & & Poor performance & 243 & 57 \\
\hline Total & 430 & 89 & Total & 430 & 100 \\
\hline \multirow{2}{*}{ Negative } & \multirow{2}{*}{52} & \multirow{2}{*}{11} & Good Performance & 22 & 42 \\
\hline & & & Poor performance & 30 & 58 \\
\hline Total & 482 & 100 & Total & 52 & 100 \\
\hline
\end{tabular}

The correlation between pupils' attitude and Mathematics performance was conducted and it was found that there is no correlation ( $r=0.007, \mathrm{p} 0.881)$ between pupils' attitude and pupils' Mathematics performance.

During interviews and focus group discussion, it was found that, most of parents or guardians do not value education instead they put more value on cattle keeping and maize cultivation. Therefore, they want their children to join them in these activities and even to force them to be married after primary schools education. Moreover, it was found that, some of parents or guardians discourage their children to go to school and even discourage them to do well in their subjects. This was pointed out by teachers during interview and pupils during focus group discussion that, parents or guardians do not like to let their children to join secondary schools.

According to [20], parents or guardian play very important role on supporting their children to learn and perform better 
in Mathematics by providing learning facilities like textbooks, good studying environment at home and encouraging them to have self-study with minimum home activities. Therefore, if parents or guardian are not interested for their children to pass their examination, they cannot provide these services and they cannot aspire their children getting good results.

\section{Discussion of Results}

The purpose of the study was to determine the attitudes of pupils towards Mathematics and thereupon establish if there exist any link between attitudes and performance. The result revealed that, more pupils (57\%) having positive attitude towards Mathematics unfortunately they had poor performance in the subject. Thus, this situation denies the concept that positive attitude leads to good performance. On other words, the positive attitude did not imply good performance. From this statement, the study revealed that there is no relationship between pupils' attitude and pupils' Mathematics performance. These findings suggest that, despite of positive attitude towards Mathematics and personal effort in learning Mathematics by the pupils, they can hardly perform poor in the subject. The previous studies conducted by $[13,15,21]$ on secondary students and [22] on pupils' Mathematics performance, also support this. Although the findings contradict the studies by [23, 24] as cited in [25] who found that, pupils' attitude in Mathematics were associated with their performance in Mathematics.

During interview, teachers $(80 \%)$ said that, pupils face difficulties in Mathematics subject because of lack of competent and professional teachers. They declared that, from standard I to V (some schools to standard VI) assigned teachers for the subject are those who failed Mathematics in secondary examination and never learnt it in teacher colleges i.e. the teaching and learning methodology. That is to say, the unprofessional Mathematics teachers are likely to continue discouraging the pupils with their contradicting strategies and methods in the classrooms. Although there are many other reasons mentioned by teachers that causes pupils to find it difficult in learning Mathematics, the lack of competent and professional teachers in many of primary schools in Tanzania is a great cause of poor performance in Mathematics.

According to [26], pupils find Mathematics difficult because, most of the teachers usually teach pupils mechanical techniques for solving certain equations or taking derivatives but not the principle. Lewis argued that, Mathematics is not about answers, it is about processes because the real building in the Mathematics sense is the true mathematical understanding, the true ability to think, perceive and analyze mathematically.

In order to rescue the situation, other studies should be conducted on the teachers teaching Mathematics subject in primary schools and the education stakeholders to work on the suggested solutions. The government in collaboration with education institutions and education stakeholders should invest more in education to improve teaching and learning environment. Lack of such initiatives will lead current interested pupils to negatively change their attitudes hence worsening Mathematics performance in Tanzania. Conducive environment of teaching and learning at school and home is required in order to support the inner motivation the pupils have for Mathematics [6].

\section{Conclusion}

In economic growth, security, development and prosperity of any country depend on the ability of its young population to obtain proficiency in mathematics [27]. When pupils exposed to mathematics at an early age, they gain skills that can be used to create a more innovative, efficient and productive workforce [27]. Poor quality teaching mathematics and unconducive teaching and learning environment have been identified as the barriers to pupils who end up in mathematics poor performing. Although there is no relationship between pupils' attitude and performance in Mathematics, still performance is a tool to change pupils' attitude. Pupils' negative attitude will be unrewarding and will ultimately discourage them from studying the subject. According to balance consistency theory, lack of consistency causes discomforts so that an individual attempt to ease the tension by adjusting attitudes or behaviors in order to once again achieve balance or consistency [28]. Hence, this difficult situation the pupils are facing on Mathematics if persists, evidently the pupils will change their attitudes towards Mathematics.

\section{References}

[1] URT (2009). Basic Education Statistics in Tanzania National Data, Ministry of Education and Vocational Training.

[2] Akinsola, M. K. \& Olowojaiye, F. B. (2008). "Teacher Instructional Methods and Student Attitudes Towards Mathematics", International Electronic Journal of Mathematics Education, GOKKUSAGl. Volume 3, No. 1, www.ieime.com Retrieved on Tuesday, $6^{\text {th }}$ October, 2009.

[3] Baloğlu, M. (2001). "Matematik Korkusunu Venmek”, Kuram ve Uygulamada Eğitim Bilrmleri Dergisi, Volume 1, No. I, pp $59-76$

[4] Peker, M. \& Mirasyedioğlu, S. (2007). "Pre $\sim$ service Elementary School Teachers' Learning Styles and Attitudes towards Mathematics", Eurasial Journal of Mathematics, Science and Technology Education, Volume 4, No. 1, pp 2126. www.ejmste.com Retrieved on Saturday, 17th October, 2009.

[5] Bandura, A. (1977). Social Learning Theory, New York, General Learning Press.

[6] Newbill, P. L (2005). Instructional Strategies to Improve Women's Attitudes towards Science. Unpublished $\mathrm{PhD}$ in Curriculum and Instruction Thesis, Virginia, Polytechnic Institute and State University.

[7] Bandura, A. (1986). Social Foundations of Thought and Action, Englewood Cliffs, NJ: Prentice-Hall. 
[8] Bandura, A. (1999). "A social Cognitive Theory of Personality", in Pervin, L. \& John, O. Handbook of Personality. New York, Guildford publications. pp 154-196.

[9] Park, S. H.; Levine, R. T.; Westerman, K. Y. C.; Orfgen, T. \& Foregger, S. (2007). "The Effects of Argument Quality and Involvement Type on Attitude Formation and Attitude Change: A Test of Dual-Process and Social Judgment Predictions", Human Communication Research, Volume 33, pp 81-102, http://www3.interscience.wiley.com/cgi-

bin/fulltext/11853507/PDFSTART Retrieved on Monday, $19^{\text {th }}$ October, 2009.

[10] Sherif, M. \& Hovland, C. (1961). Social Judgment, Assimilation and Contrast Effects in Communication and Attitude Change, New Haven, Yale University Press.

[11] Sherif, C., Sherif, M. \& Nebergall, R. (1965). Attitude and Attitude Change. Philadelphia, PA: Saunders.

[12] Valery, N. (2014). Attitude of secondary school students towards mathematics and its effects on their performance in Bagamoyo district, Tanzania. M. A. (Education) Thesis, Dar es Salaam, University of Dar es Salaam.

[13] Mwakitalima, B. A. (2008). Influence of Attitudes and Norms on Students' Mathematics Learning: A Case Study of Meta and Mbeya Secondary Schools in Mbeya Region, M. Ed (Science Education) Dissertation, Dar es Salaam, University of Dar es Salaam.

[14] Rukando, N. D. (2006). Girls' Attitude and Performance in Mathematics: A Comparative Study Between Rural and Urban O-level Secondary Schools in Mora region, Tanzania, M. A. (Education) Thesis, Dar es Salaam, University of Dar es Salaam.

[15] Ngenzi, S. S. (2005). Girls' Attitudes and Performance in Science and Mathematics in Selected Low and High Performing Schools in Tanzania, M. Ed (Science Education) Dissertation, Dar es Salaam, University of Dar es Salaam.

[16] Marcoulides, G. A., \& Hershberger, S. L. (1997). Multivariate Statistical Methods: A First Course, Mahwah, NJ: Lawrence Erilbaum Associates Publishers.

[17] Comrey, L., \& Lee, H. (1992). A Furst Course in Factor Analysis. Hillsdale, NJ: Lawrence Erlbaum.

[18] Kaiser, H. F. (1960). "The Application of Electronic Computers to Factor Analysis", Educational and Psychological Measurement, Volume 20, pp 141-151.
[19] Rummel, R. J. (1970). Applied Factor Analysis, Evanston: Northwestern University Press.

[20] Bhalalusesa, E. P. (2003), "Beyond Access: Analysis of Girls and Women's Participation and Performance in Education in Tanzania", Paper in Education and Development, Dar es Salaam, KAD Associates, Volume 23, pp 69-85.

[21] Mensah, J. K., Okyere M. and Kuranchie, A. (2013). Student attitude towards Mathematics and performance: Does the teacher attitude matter? Journal of Education and Practice, ISSN 2222-1735 (Paper) ISSN 2222-288X (Online) Vol. 4, No. 3, Retrieved on Wednesday, $15^{\text {th }}$ April, 2020.

[22] Phonguttha, R., Tayraukham, S. \& Nuangchalerm, P. (2009). "Comparisons of Mathematics Achievement, Attitude towards Mathematics and Analytical Thinking between Using the Geometer's Sketchpad Program as Media and Conventional Learning Activities", Australian Journal of Basic and Applied Sciences, Volume 3, No. 3, pp 3036-3039, INSI net Publication.

[23] Olatoye, R. A. (2001). A Causal Model of School Factors as Determinants of Science Achievement in Lagos State Secondary Schools. Unpublished PhD Thesis, lbadan, University of lbadan.

[24] Adesokan, C. O. (2002). Students attitude and Gender as Determinants of Performance $\mathrm{m}$ JSS integrated Science. Nigeria Unpublished B. Ed project, University of Ado-Ekiti.

[25] Olatude, Y. P. (2009). "Students Attitude towards Mathematics and Academic Achievement in Some Selected Secondary Schools in Southwestern Nigeria“, European Journal of Scientific Research, EuroJournals Publishing, lnc. Volume 36, No. 3, pp 336-341, http://www.eurojournals.com/ejsr.html Retrieved on Friday, $19^{\text {th }}$ March, 2010.

[26] Lewis, R. H. (2010). Mathematics: The Most Misunderstood Subject, New York, Rose Hill Campus Bronx, http://lwww.fordham.edu/academics/programs_at_fordham_/ mathematics_deartme/wha_math/index.asp Retrieved on Friday, 9th April, 2010.

[27] Mohammed Khalid (1 Oct 2017) How to Reduce Poverty in Developing Countries. Retrieved on Friday June 1, 2018 from https://borgenproject.org/reduce-poverty-in-developingcountries/

[28] Heider, F. (1958). The Psychology of Interpersonal Relations, New York, Wiley. 